\title{
A GUIDE TO THE PITFALLS OF IDENTIFYING PRICE DISCRIMINATION
}

\author{
JOHN R. LOTT, JR. and RUSSELL D. ROBERTS*
}

\begin{abstract}
This paper demonstrates that plausible cost-based explanations exist for what are commonly perceived to be cases of price discrimination. We explain such commonly discussed problems as the price spreads of retail gasoline products, the "high" price of dinners at restaurants, the "high" price of popcorn at movie theaters, and the fact that airline ticket prices vary with how long the ticket is purchased before the flight's departure. Our explanations benefit from not relying on consumer ignorance or implicit collusion among numerous sellers.
\end{abstract}

\section{INTRODUCTION}

Many economists explain pricing anomalies by invoking "monopoly power." To paraphrase H. L. Mencken, such answers are all too frequently simple, neat, and wrong. By examining specific pricing anomalies, we show that cases of alleged price discrimination may simply involve unrecognized costs. We examine the pricing of retail gasoline products, the "high" price of dinners at restaurants, the "high" price of popcorn at movie theaters, and the fact that airline ticket prices vary with how long the ticket is purchased before the flight's departure. While hardly a comprehensive selection, each case involves what has been perceived as an "obvious" case of price discrimination.

When two products appear identical and sell for different prices, price discrimination is often invoked instead of seeking unobserved cost or quality differences. Colleagues have assured us that because some colas are priced below some seltzers,

- Anderson Graduate School of Management, University of California-Los Angeles and Olin School of Business, Washington University. We wish to thank Armen Alchian, Thomas Borcherding, David Butz, Gertrud Fremling, William Gale, Neal Geary at Amoco, Russ Gibson at Chevron, David Hirshliefer, Ben Klein, Bob Kovacovitch at Shell, Sharon Kupfer, Earl Thompson, Michael Waldman, Ralph Winter, a particularly diligent anonymous referee from this journal, and participants at the 1988 Western Economic Association Meetings for helpful comments and discussions, and Kavita Vora and Ed Quigley for research assistance. Any remaining errors are our own. there must be monopoly power because the colas have the seltzer cost plus the additional cost of the flavoring. This explanation ignores the possibility that water quality and carbonation may have to be higher when pure seltzer is not masked with cola flavor. We have had colleagues tell us that Michelin produces tires for Sears identical to its own but charges different prices for the two brands to price discriminate. While Michelin does produce tires for Sears, we have no reason to believe that the quality is identical in both cases. Consumer Reports [1973], for example, finds Michelin tires are more expensive than Sears tires, but they are also of higher quality.

Quality differences such as the above often explain alleged cases of price discrimination. Our focus here is on cost differences. Allegations of price discrimination often ignore differences in costs beyond the marginal cost of production. The examples that follow show how opportunity costs, such as inventory and overhead costs, are sufficiently large to explain price differentials in a competitive world of informed consumers.

\section{EXPLANATIONS OF GASOLINE PAICING}

Two puzzles have been noted with regard to retail gasoline pricing. First, the absolute price spread between full-service and self-service gasolines is smallest for 
super unleaded compared to regular unleaded and regular leaded gasoline. The second puzzle is that while the production costs of leaded and unleaded gasoline differ by approximately a penny, the price of regular leaded gasoline is more than a penny lower.

Two answers based on price discrimination have been supplied to explain the price differential between leaded and unleaded. The first is that leaded gasoline is the "fighting grade" - the low leaded price is posted to lure unsuspecting unleaded customers into the station who succumb to the higher price rather than search elsewhere. This explanation requires a very short term memory for consumers who are repeatedly fooled, and laziness on the part of competing gasoline stations (which may only be across the street from one another) that fail to lower information costs by advertising. The second explanation is that gasoline stations have monopoly power. Unleaded customers are hypothesized to have higher search costs than leaded customers. Stations then exploit unleaded customers by charging them higher prices. ${ }^{1}$

\section{An Alternative Explanation}

The production cost is only one component of the cost of supplying gasoline to consumers. The cost of selling leaded and unleaded gasoline need not be the same. One difference is the size of the transaction. It is cheaper to sell a single 15 gallon purchase than two purchases of $7.5 \mathrm{gal}$ -

1. These monopoly explanations were attributed to Nick Nichols in the "Puzzles" section of the Joumal of Economic Perspectioes. We have heard both of these explanations many times from others as well. As evidence of monopoly power, Barry Nalebuff in "Puzzles" cites Mixon and Uri [1987] who find that states with a higher ratio of cars using unleaded gasoline to cars using leaded have a larger difference, on average, between the price of unleaded and leaded gasoline. They argue that the ratio of cars using unleaded to cars using leaded is a proxy for the elasticity of demand. It seems a rather poor proxy. None of the explanations that posit monopoly power show that it is large enough to explain the size of the differential.
Ions each because of the fixed costs associated with a transaction-making change, noting the number of gallons, turning the pump off and on, etc. In addition, a larger number of smaller transactions makes for more traffic and congestion in the station, reducing total sales or requiring a larger station. Another cost difference between grades is the slower flow rate from the nozzle of the unleaded pump relative to the leaded nozzle. It would be cheaper to serve a leaded customer than an unleaded one because the leaded customer ties up the pump for a shorter period of time. ${ }^{2}$

Under perfect competition, the seller sets the unleaded price, $P_{u^{\prime}}$ so on average, revenue, which equals $P_{\mu}$ times $G_{u}$ (the average number of gallons purchased of unleaded), must cover the costs of serving the customer and $w$, the wholesale price of gasoline. The cost of serving the customer is approximated by the number of minutes it takes to make the transaction multiplied by the per minute rental rate, $r$ sufficient to cover the overhead of land rent, depreciation of capital, and labor costs. This is the implicit rental rate that covers these costs. There are two aspects to the time cost. One is the time to physically pump the gasoline, $t_{u} G_{u}$ where $t_{u}$ is the time (in minutes) to pump a gallon. The second is the time a transaction takes in addition to pumping gasoline: the time it takes to get out of the car, make payment, and pull out of the station. This time per transaction, which we will assume is the same for leaded and unleaded consumers, is denoted by $F$ and is measured in minutes. So:

$$
P_{u} G_{u}=r\left(t_{u} G_{u}+F\right)+w \cdot G_{u}
$$

or

$$
P_{u}=\left[r F / G_{u}\right]+\left(w+r t_{u}\right)
$$

2. California, and perhaps other states, places a legal maximum on the pumping speed, which may affect this differential. 
The leaded price, $P_{L}$, assuming that the wholesale price is smaller by $\$ .01$, is given by

$$
P_{L}=\left[r F / G_{L}\right]+\left(w-.01+r t_{L}\right)
$$

The expected differential is then:

$$
\begin{aligned}
& P_{u}-P_{L}=r\left(t_{u}-t_{L}\right) \\
& +\left[r F\left(G_{L}-G_{u}\right) / G_{L} G_{u}\right]+.01 .
\end{aligned}
$$

There are three parts to the differential. The last term is the wholesale difference. The second term is the difference in cost due to the fixed cost per transaction-if the average leaded purchase exceeds the average unleaded, then the fixed cost is spread over more gallons, reducing the price of leaded. The first term captures the difference in the time to pump a gallon of leaded and unleaded. It is a per gallon rental of the pump. The implicit per minute rental rate on the pump, $r$, also affects the absolute differential. For example, regions with higher land rents should have a larger differential if the first and second terms are not trivial.

Cars using leaded gasoline have, on average, larger gas tanks than cars using unleaded gasoline. The increase in gasoline prices in the 1970 s caused substitution towards smaller, more fuel efficient cars during the time unleaded gasoline became required in new cars. The size of the tanks fell at the same time. ${ }^{3}$ If the average transaction is larger for leaded gasoline, the fixed cost per transaction will be spread out over a larger number of gallons. We predict that self-service leaded transactions involve larger average purchases

3. Peter Hartley of Rice University tells us that in Australia, where new cars were not required to use unleaded gasoline until relatively recently, there is no price spread between leaded and unleaded gasoline. than self-service unleaded transactions. Since the middle of 1981, the real price of gasoline has fallen and new cars have gotten larger. The resulting increase in gas tanks and average transactions for unleaded cars implies a narrowing differential. The average unleaded/leaded differential in the United States was 4.44 in 1978 and peaked in real terms in 1983. It has fallen nearly steadily since 1983 and is even negligible in some markets today.

In a competitive world, equation (4) is valid in the absence of other costs that are not constant per gallon. Assume it takes three seconds (.05 minutes) longer to pump a gallon of unleaded and two additional minutes to purchase gasoline outside of the pumping, $F$. Assume an average unleaded transaction is eight gallons and an average leaded transaction is $\mathbf{1 2 . 5}$. Equation (4) becomes

$$
\begin{aligned}
P_{u}-P_{L} & =r(.05)+[2 r(.045)]+.01 \\
& =.14 r+.01
\end{aligned}
$$

To create a differential of $\$ .06$, the per minute rental rate must be $\$ .05 / .14$ which equals $\$ .35$, or $\$ 21$ per hour. Assume that the island is in demand eight hours per day. Then the daily rental is $\$ 168$ and the monthly is $\$ 5040$. A four-island self-service station would be predicted to have a rental of $\$ 20,160$. In the Los Angeles area, according to conversations with oil company executives, the monthly payment from a dealer to the oil company leasing the station with its pumps and storage tanks might be as high as $\$ 10,000$. When labor costs are included, the $\$ 20,160$ figure is plausible.

4. Even though the gas tanks of cars using leaded gasoline are larger than those using unleaded, which average transaction is larger is an empirical question. The direction of the self-service premium predicts that leaded transactions are larger on average. Below we discuss why the average purchase of full-service unleaded may be smaller. Our point here is to show how price is a function of cost. 
Unfortunately, stations we examined only keep track of total gallons sold and not the number of customers or average size of transaction. So we are unable to provide direct evidence of the impact of transaction size. We found further indirect evidence by looking at the price differential between full- and self-service gasoline by grade of gasoline. The fixed cost per transaction for full-service gasoline is larger than that for self-service. This is an obvious reason for why full-serve is more expensive than self-serve. We might expect these costs to be the same across grades of gasoline. It takes an attendant just as long to check the oil and air pressure and clean the windows for cars that use super unleaded as it does for cars using standard unleaded. But in fact, the differential is typically larger for regular unleaded or leaded than for super.

We can use the logic of equation (4) to derive the full-serve/self-serve differential for leaded gasoline:

$$
P_{F L}-P_{L}=\left[r F+s r F+e s / G_{F L}\right]-\left[r F / G_{L}\right]
$$

The subscript $F L$ refers to full-service leaded, $G_{L}$ is self-serve, $s$ is the extra time (in minutes) to provide full-service, including the extra time at the pump, and $e$ is the extra labor cost (per minute) to provide full-service. If purchasers of every grade used the same extra amount of time, $s$, and bought the same amount, the differential across grades would be a constant. But as equation (6) shows, as fullserve purchases decrease relative to the size of self-serve purchases, the differential increases. The intuition is the same as before-smaller purchases mean that the fixed cost (in this case the extra cost of labor services and time to provide full service) is spread over a smaller number of gallons, so the differential is larger.

We assume that the opportunity cost of time for those who use super unleaded is higher than for those who use other grades of full service. Both full- and self- serve super unleaded customers are more likely to wait until their tanks are almost empty and then fill them completely. Customers demanding leaded gasoline and, to a lesser extent, regular unleaded are likely to be poorer and have lower time costs than those using super unleaded. When they use full service, they are more likely to purchase a small amount to obtain the service and bear the additional time cost of filling up the rest of the tank later. In a competitive market, stations charge a premium to cover the cost of this behavior.

A survey of sixty-six American cities in 1983 (National Petroleum News Factbook [1984]) found that in the sixty-five cities for which all the data were available, fifty had a substantially smaller (usually ranging from 5-15థ) full-serve premium for super unleaded than for either leaded or regular unleaded. In the remaining fifteen cities, the premium was within 14 of the lowest of the other two. Interestingly, the regular unleaded premium for full-serve was very close to that of leaded.

A two-part tariff-a fixed price for the service (or for using the pump in the case of self-service) and a per gallon price for the gasoline-also covers costs. A problem with this scheme is monitoring the attendant who can pocket the fixed part of a cash payment unless the pump cheaply and accurately registers the number of transactions. As noted above, current pumps do not. The failure to observe a two-part tariff is also inconsistent with an explanation based on monopoly powerif stations have monopoly power then a two-part tariff that can be cheaply administered is also likely to improve profits if the customers of different grades impose different costs on the firm.

Whether transaction size can explain the variation in gasoline pricing is an empirical question. Our goal in this section has been to show that plausible variations in purchase size can lead to the observed variation in prices. Even under perfect 
competition, real world pricing is not simply a matter of wholesale cost plus a constant markup. Not only will prices vary with purchase size, but variations in prices across grades may arise from many other sources. For example, the inventory costs of each grade of gasoline may differ if there are differences in the predictability of demand across grades. Even prices for a single grade will vary across stations due to quality differences; stations compete on many dimensions including quality of service and expected queuing time during times of peak demand. The failure to explain retail price variations with wholesale price variations is simply not evidence of monopoly power.

\section{THE "HIGH" PRICE OF COFFEE, TEA, AND DINNER IN RESTAURANTS}

Several authors (e.g., Heyne, [1987, 191-2]) attribute the higher prices for the same, meal at dinner relative to lunch to price discrimination. While the size of dinners are assumed to be larger, this is not thought to be sufficient to explain the price differential. According to Heyne, lunch-time diners have searched more and thus have more elastic demand curves for lunches. We have seen no evidence that the typical restaurant has monopoly power. Whether lunch patrons have more information than dinner patrons is another empirical question.

A different explanation for the price differential, consistent with competition, is that there is quicker turnover at lunch because diners face more severe time constraints. Analogous to our discussion of gasoline pricing, the cost of producing a meal is not just the cost of the food but also the rental cost of the space used during the meal. The more leisurely dinners that people enjoy result in a higher implicit rent at dinner time embodied in the prices. Dinner meals are larger for the same reason-the patrons have more time to enjoy them. While two-part tariffs are also theoretically possible to separate the cost of the food from that of the rent, we assume that explicitly charging for the time at the table, say in the form of a ticking meter, would affect the quality of the meal.

This opportunity cost of using a table explains why the retail over wholesale mark-up in a restaurant varies across the types of food. For instance, coffee, tea, and wine are priced seemingly so far above their "marginal costs" because people either linger over these items, or linger longer over meals that include them. The prices of these items must include the cost of renting the table. This implies that for items with little or no labor preparation costs, such as beverages, the mark-up is largest for those beverages that people linger over longest. So wine should have a larger absolute difference between its retail and wholesale price compared to beer, and both are going to be larger than for a soda. ${ }^{5}$ Alcohol and coffee also have large inventory costs. Restaurants typically stock all types of liquor and will throw out many cups of coffee over the course of a day to insure its freshness.

If this explanation is correct, why doesn't McDonald's charge a lower price for take-out items? If McDonald's charged a lower price for take-out, they would incur monitoring costs making sure takeout customers did not stay inside and use a table anyway. Many restaurants do, however, charge a lower price for takeout.

A related puzzle is why restaurants offer free refills of coffee and iced tea. One answer is that most people wish to drink more than one cup or glass, and that rather than have the waitress keep track of all the refills (which she could chisel on in search of larger tips), the restaurant sets

5. There is the additional cost of the liquor license in the case of alcohol. 
the price for the bottomless cup or glass high enough to cover the costs of the expected multiple units. If the cost of keeping track of the refills is small relative to the variance in consumption, offering a zero marginal price would make no sense.

The right answer may be as follows: for iced tea there is very little problem because people do not linger over iced tea. For coffee, it is not really a bottomless cup. The free-refill offer is mainly an offer to freshen the lukewarm cup with a hot splash. ${ }^{6}$

This analysis of restaurant pricing answers the annoying comment of non-economists that restaurants "break even" on their food but "make all their profits" on alcohol. When pressed, what people mean by this statement is that restaurants have monopoly power and choose to exercise it on the drinks rather than the food. This statement is half-right. Restaurants in a competitive world do break even on the food. They appear to make all their profits on the drinks, but the drinks are also a large part of their costs. The high cost of liquor is not so much due to the wholesale price but to the cost of renting a clean well-lighted place to drink.

\section{THE PRICING OF POPCORN AT MOVIE THEATERS}

At the movies, a large container of popcorn might cost $\$ 3.00$ for $50 \%$ worth of kernels. Candy and sodas also seem expensive. One explanation of the high price of

6. We thank Earl Thompson for this institutional detail confirmed by waitresses. This explanation would predict that some restaurants will offer customers the privilege of costly refills for those customers who wish to linger. It correctly predicts that bottomless coffee at breakfast is cheaper than later in the day since people tend to hurry over breakfast. Restaurants do not set a high price of wine and offer free refills, because the variance of wine consumption exceeds that of coffee, and is quite large-some people would not just linger, but stay indefinitely. popcorn is monopoly power. ${ }^{7}$ The simple version of the monopoly power argument is that you are stuck in the theater, the theater bars you from bringing in your own food and exploits your immobility by charging a high price for popcorn. Related claims are made about the pricing of food at athletic events and university cafeterias.

If all movie viewers ate popcorn at the movies and ate the same amount, the question of pricing at the concession stand would be of little interest. The only thing that would matter would be the combined price of the ticket and the popcorn. We have one estimate that the average patron spends about 404 on popcorn, so only a relatively small fraction of customers purchase popcorn. The sophisticated version of the monopoly power explanation adds that there is a positive relationship between willingness to pay for the movie and willingness to pay for refreshments. By charging a high price for popcorn, the theater is able to extract consumer surplus.

Friedman [1986] suggests a competitive explanation. There are high costs of providing refreshments (the staffing and capital costs of the concession stand) over the short period of time demand exists. As a result, popcorn is expected to have a high price because its true cost is indeed high. This explanation is akin to the explanation of leaded and unleaded prices given above. In both cases, price must be high enough to cover both the fixed and marginal cost.

If true, multiscreen theaters should have lower popcorn prices than single

7. Another alleged example of monopoly power of theaters is the discounts offered to senior citizens and children under twelve, a seemingly obvious case of price discrimination. Yet many senior citizens and children attend matinees, which have lower attendance. Theaters do typically charge lower rates for matinees, and in Los Angeles the senior citizen discount typically results in a price identical to the matinee price. An interesting puzzle is why theaters do not charge separate admission prices for the weekday and the weekend. In some places they do, but in general they do not. This is surprising under any hypothesis. 
screen theaters. Holding the number of customers constant, when there are many screens, the starting times can be staggered such that there is less queueing at the concession stand, more customers can be served, and the fixed cost of the concession stand can be spread out over a larger number of customers. We have some crude evidence on these issues from the Los Angeles area shown in Table I. The first five entries are theaters in high rent areas in Los Angeles. The Popcorn Palace is a popcorn store in a swanky mall. The drugstore in Century City is in an extremely high rent area. The true price is a little higher, and the marginal cost a little lower since you must fill the container yourself. The Popcorn Palace popcorn was of slightly lower quality than movie popcorn - the corn was smaller. ${ }^{8}$

Popcorn at movie theaters is "expensive," but it is not much more expensive than at other locations, at least in this small sample. There is, however, no evidence for the multiscreen effect-many theater chains in the L.A. area charge the same price for popcorn at all of their locations regardless of the number of screens. For example, the Cineplex Odeon chain charges the same price for popcorn at their eighteen screen theater in Universal City as they do at locations with a single screen. The monopoly explanation must also explain why prices are the same for all movies and why they do not vary within a city. Is the relationship between elasticity of demand for popcorn and willingness to pay for movies constant across the city?

There is a competitive explanation that explains why each chain sets a uniform price. Theater owners and film owners share ticket revenue. The owner of a likely blockbuster film may get as high as 90 percent of revenue and the theater owner 10 percent. A film with less certain popular-

8. Quality assessment based on a small field sample conducted by authors. ity might be split 50-50. Presumably this is a risk sharing agreement due to the high degree of uncertainty about the drawing power of a film before its release. Since theater owners only get a fraction of the ticket revenue, but all of the concession stand revenue, they could charge a high price for popcorn sold at the screening of a blockbuster and only lose 104 on the dollar for every discouraged customer. The owner of the film anticipates this problem, however, and often restricts concession prices in the rental agreement. In addition, since a theater owner may move a film to another of his theaters, by pledging a uniform price of concessions across theaters he commits to not sabotaging ticket revenue by taking advantage of high concession stand prices at a different theater. ${ }^{9}$

Competition among theaters insures that expected ticket revenue covers the overhead of the building and the ushers while concession stand revenue covers the overhead and labor costs of the concession stand. A theater owner who tried to charge prices above marginal cost for his concessions would lose popcorn-eating customers to his competitors as well as being forced by film owners to accept a smaller fraction of ticket revenue.

Why do theater owners not allow patrons to bring their own food into the theater if they are only making normal profits on the concession stand? In fact, many chains in the L.A. area allow customers to bring in their own food. There are some restrictions, typically the forbidding of cans and bottles on grounds of danger. Some theaters only allow you to bring in food that is the type they sell, a complete contradiction of the monopoly explanation. Owners of these theaters said that they did not want to expose patrons to

9. If the cost factors we mention above are significant, then even though nominal popcorn prices are the same across theaters the costs are not. So the theater chain can exploit demand differences by shifting the movie from one theater to another. 
TABLE I

\begin{tabular}{lcccc}
\hline & & \multicolumn{3}{c}{ Price of Popcorn } \\
\cline { 4 - 5 } Theater & \# of Screens & Small (oz.) & Medium (oz.) & Large (oz.) \\
\hline UA-Westwood & 3 & $\$ 1.75(46)$ & $\$ 2.75(85)$ & $\$ 3.50(130)$ \\
Landmark-W. LA & 4 & $\$ 1.50(40)$ & $\$ 2.25(85)$ & $\$ 3.25(130)$ \\
Laemmle-S. Monica & 1 & $\$ 1.50(46)$ & $\$ 2.25(85)$ & $\$ 3.25(130)$ \\
Cineplex-Odeon-Bev. Hills & 13 & $\$ 1.50(-46)$ & $\$ 2.40(-85)$ & $\$ 3.00(-130)$ \\
AMC-Cent. City & 14 & $\$ 1.25(40)$ & $\$ 1.95(85)$ & $\$ 2.95(120)$ \\
Popcorn Palace-W. L.A & 0 & $\$ 1.00(64)$ & & \\
Drugstore in Century City & 0 & $\$ 1.00(-40)$ & & \\
\hline
\end{tabular}

odors that they were not used to in a movie theater such as fried chicken or Mexican food. Presumably, some items would also pose larger clean-up problems.

\section{THE "HIGH" PRICE OF TRAVELUNG BY AIRPLANE ON SHORT NOTICE}

A frequent example of price discrimination given by economists is that individuals who want to fly on short notice must pay a higher price than individuals who can carefully plan their trips and thus check different fares well in advance. The explanation assumes that travelers who fly on short notice have more inelastic demand than those who can make more leisurely plans. One puzzling aspect of this claim is exactly how these prices above marginal cost are maintained when numerous potential competitors exist and the cost of checking the various fares is so low. If an executive wants to fly on short notice, it requires that his secretary make only a few calls to check competing rates or, even better, call someone who specializes in checking the different rates-a travel agent. The fact that these differentials exist despite such low costs of shopping for different fares should at least give one pause before immediately assuming price discrimination. ${ }^{10}$

An alternative answer is that the airline is also providing the customer with a service: the ability to purchase a ticket at the last minute. This service is costly and involves a cost analogous to providing inventories. When consumers go to the grocery store to buy milk they are confident that it will be there on the shelves, but consumers pay a higher price for milk because of this service. Grocery stores do not know with perfect certainty what the demand for milk will be on any particular day so they must purchase more milk than they think they will sell on average in order to provide consumers with the assurance that it will be there when they want it. On average, stores will throw away unsold milk, a cost which will be reflected in the competitive price for the product.

10. Another puzzle is the requirement that consumers have to spend a Saturday night at their destination in order to receive the discount. This is typically explained as an example of price discrimination against business travellers, but it may only be a form of peakload pricing if those who stay over on Saturday night travel on Sunday, the quietest time of the week. The puzzle remains as to why there is not an explicit discount for returning on Sunday, but this is also a problem for the price discrimination explanation. 
In the case of airline seats, the opportunity cost of keeping some seats available until the last minute is that they will go unused. ${ }^{11}$ The limited number of seats that airlines make available for advance purchase discounts shows how easy it is for airlines to sell advance tickets. If they could not sell many of these discount tickets, the restriction on the number sold would be superfluous. This also explains why airlines have penalties for cancelations of these discount fares and not for reservations at the higher price. A customer who cancels his reservation at a date closer to the planned departure than when he purchased it lowers the probability that the airline will be able to fill the seat with another paying passenger.

For an airline to be willing to hold seats for last minute travelers, they must make the same expected revenue from these seats as they do from those seats purchased in advance. For example, if, on average, one-half of the seats set aside for last minute travelers go unsold, and if they all could have been sold at the advanced ticket price, the premium for late travel compared to early would be 100 percent. ${ }^{12}$

If this explanation is correct, we should observe similar pricing for other "perishable" goods with uncertain demand. One interesting example is tickets to sporting events, concerts, or musicals. Ticket brokers (or scalpers, the informal equivalent) will charge a premium for tickets the day right before the performance. For our explanation to be correct, they must also fail to sell some tickets because of uncertainty.

11. Standby fares do exist and are often used by airline employees and their immediate relatives, but these fares are only a smail fraction of the ticket price that the company would have received if it had sold it even as a discount fare to a paying customer. Often the price paid by the employee is only the tax that would have been levied on a non-standby fare and that the airline must pay the government.

12. If all the tickets could not have been sold at the advance price, we would expect the airline to adjust the ratio of early to late seats.
This does occur for sporting events, where one of the authors has seen regular scalpers refusing to discount deeply even after the game has started. Related examples are the booking of hotel rooms and rental cars in advance. The rates are typically lower for rentals with advance notice.

If the cost differences we have identified are important, then a monopolist would also wish to take them into account when setting prices. Our explanations do not prove that pricing anomalies are due only to cost differences. In the case of airline pricing, discounts for advanced reservations were offered both before and after $\mathrm{CAB}$ deregulation. Our explanation is able to explain, however, why advanced reservation discounts exist even on highly competitive routes after deregulation.

\section{CONCLUSION}

We have examined four cases of pricing often explained by price discrimination and offered plausible explanations based on fixed costs, time costs, or the costs of providing inventories. Explanations that rely on price discrimination and monopoly power frequently ignore the costs of providing more than just the most obvious services. They rely on very short memories on the part of consumers who are repeatedly fooled, firms which do not seem to have much of a desire to make money, or collusion (explicit or implicit) even when the number of firms is large. While the costs of acquiring information are undoubtedly high in many cases, the use of information costs to explain price discrimination and the ease of implicit collusion for such things as airline tickets, where the cost of acquiring information is a simple telephone call, lacks credibility.

It is always easy to invoke monopoly power to explain pricing anomalies that seem on first glance to be inconsistent with competition. But there are frequently explanations, as we have provided here, that are consistent with competition. The 
challenge is to provide empirical evidence of the magnitudes of the effects claimed on either side, or additional implications that allow the hypotheses to be tested. We have tried to provide stylized facts that are consistent with competitive explanations as well as showing that plausible estimates of costs can explain observed pricing.

\section{REFERENCES}

Consumer Reports, October 1973, 608-9.

Friedman, David. Price Theory: An Intermediate Text. Cincinnati: South-Western Publishing, 1986.

Heyne, Paul. The Economic Why of Thinking. Chicago: Science Research Associates, 1987.

Mixon, J. Wilson Jr. and Noel Uri. "Price Discrimination and Free-Entry Markets: The Case of Gasoline." Applied Energy 26, 1987, 1-7.

National Petroleum News Factbook, Des Plaines, IL: Hunter Publishing Co., 1984; 1987.

"Puzzles." Journal of Economic Perspectives, Summer $1987,185-91$. 